\title{
Assessment of clinical and radiographic outcomes of guided bone regeneration with dehydrothermally cross-linked collagen membrane around peri-implant dehiscence defects: Results from a 3-year randomized clinical trial
}

\author{
Jae-Hong Lee ${ }^{1 \dagger}$, Su-Hyun Park ${ }^{2 \dagger}$, Do-Hyung Kim¹, Ui-Won Jung ${ }^{2 *}$ \\ ${ }^{1}$ Department of Periodontology, Wonkwang University Daejeon Dental Hospital, Institute of Wonkwang Dental Research, Wonkwang University College of \\ Dentistry, Daejeon, Korea \\ ${ }^{2}$ Department of Periodontology, Research Institute for Periodontal Regeneration, Yonsei University College of Dentistry, Seoul, Korea
}

The objective of this study was to determine the clinical and radiographic efficacy of dehydrothermally (DHT) cross-linked collagen membrane in the treatment of peri-implant dehiscence defects through a 3-year randomized clinical trial. This study involved a total of 30 patients in the preliminary study, but only 19 patients (experimental group [DHT cross-linked collagen membrane, $\mathrm{n}=6$ ] and control group [non-cross-linked collagen membrane, $\mathrm{n}=13$ ]) were followed-up for 3 years after setting the baseline immediately after final prosthesis. The mean and standard deviation of each clinical measurement (probing pocket depth and width of attached gingiva) and radiological measurement (marginal bone level and clinical crown-to-implant $[\mathrm{C} / \mathrm{I}]$ ratio) indices were determined and compared using the nonparametric Mann-Whitney test at the 95\% confidence level. No significant complications, such as surgical site exposure and or severe infection, was observed during the follow-up period. Marginal bone loss in the experimental group and control group were $0.14 \pm 0.40 \mathrm{~mm}$ and $0.08 \pm 0.30 \mathrm{~mm}(p=0.631)$ respectively. The clinical $\mathrm{C} / \mathrm{I}$ ratio change in the experimental group and control group were $0.25 \pm 0.29 \mathrm{~mm}$ and $0.12 \pm 0.23 \mathrm{~mm}(p=0.557)$ respectively. The width of attached gingiva in the experimental group and control group were $2.27 \pm 2.49 \mathrm{~mm}$ and $2.58 \pm 1.18 \mathrm{~mm}(p=0.732)$ respectively. The differences were not statistically significant. These results suggest that the experimental group and control group had similar clinical outcome, and highlight the potential of DHT crosslinked collagen membrane for guided bone regeneration around peri-implant dehiscence defects.

Key Words: Bone regeneration, Collagen, Membranes, Randomized controlled trial

(a) This is an open-access article distributed under the terms of the Creative Commons Attribution Non-Commercial License (http://creativecommons.org/licenses/by-nc/4.0) which permits unrestricted noncommercial use, distribution, and reproduction in any medium, provided the original work is properly cited.

\section{INTRODUCTION}

Bone tissue of sufficient quantity and quality is an important factor for successful osseointegration and long-term survival of dental implants. However, patients with periimplant defects that are not suitable for reconstructive im- plants due to various reasons such as severe periodontitis are often encountered in the clinical setting. Guided bone regeneration (GBR) is a useful approach for the reconstruction of alveolar defects [1]. In particular, a combination of resorbable collagen membrane and anorganic bovine bone graft is used as the standard method for GBR; this method

Received August 27, 2018; Revised December 1, 2018; Accepted December 4, 2018

Corresponding author: Ui-Won Jung, Department of Periodontology, Yonsei University College of Dentistry, 50-1 Yonsei-ro, Seodaemun-gu, Seoul 03722, Korea.

Tel: +82-2-2228-3185, Fax: +82-2-392-0398, E-mail: drjew@yuhs.ac

†These authors contributed equally to this work.

Copyright () 2019, Oral Biology Research Institute 
is widely and routinely used with successful results in many clinical studies [1,2].

GBR is a technique that involves the use of bone graft materials and membranes to induce selective proliferation of bone tissue and block epithelial and connective tissues for the functional recovery and rehabilitation of bone defects $[3,4]$. For ideal bone regeneration, membranes used for GBR must have biocompatibility, selective cell blockage of the gingival connective tissue, and space-maintaining ability. For this purpose, expanded-polytetrafluoroethylene, a non-resorbable membrane, was successfully used very widely, but its clinical use is now limited due to the need for another surgery to remove the membrane as well as the high risk of membrane exposure [4].

Various resorbable membranes, such as collagen, polyglycolide, and polylactic acid, have been developed and used in order to overcome the shortcomings of nonresorbable membranes. Currently, resorbable collagen membranes are most often used [5]. In particular, noncross-linked collagen is widely used in the clinical practice due to its low antigenic properties and cellular toxicity, clinical manageability, and regenerative ability that is similar to that of non-resorbable membranes [5,6]. However, despite many clinical and histological advantages, the lack of selective tissue blockage that hinders sufficient bone regeneration and maturation due to fast resorption is a major disadvantage of non-cross-linked collagen $[7,8]$.

Physical and chemical cross-linking methods have been researched and developed in order to overcome the shortcomings of non-cross-linked collagen membrane and improve the quality of the membrane [9]. Among these, collagen membrane made with the dehydrothermal (DHT) cross-linking technique is reported to have higher heat stability and mechanical strength, increased resistance to enzyme activity, as well as sufficient vascularization and good biocompatibility [10]. Although in vitro and animal studies on DHT cross-linked collagen membrane have progressed, clinical studies of the biocompatibility and bone regenerative abilities compared with non-cross-linked collagen are limited. Therefore, we conducted a randomized, prospective study to compare the clinical feasibility between DHT cross-linked and non-cross-linked collagen membranes used to treat peri-implant dehiscence defects. With respect to comparison of clinical, radiological, and histological results between the primary and secondary implant surgery through this prospective study, DHT cross-linked collagen membrane showed biocompatibility and bone regenerative abilities similar to those of non-cross-linked collagen membrane [11]. The purpose of the present study, which was conducted as a follow-up study, is to comparatively evaluate the clinical and radiological efficacy of DHT crosslinked collagen membrane in the treatment of peri-implant dehiscence defects through a 3-year randomized clinical trial.

\section{MATERIALS AND METHODS}

\section{Study population}

A randomized, prospective study was conducted on 30 patients who underwent single implant surgery with GBR at the Department of Periodontology, Yonsei University Dental Hospital (Seoul, Korea) between August 2013 and October 2014. This study was approved by the Institutional Review Board (IRB) for Clinical Research at Dental Hospital of Yonsei University (approval no. 2-2013-0021). The study was conducted on healthy adults (including those with controlled medical or dental diseases) aged 20 years or older with a vertical dehiscence defect measuring more than $3 \mathrm{~mm}$ around the buccal side of the implant. Criteria for exclusion from the analysis were as follows: severe and/or uncontrolled systemic disease, untreated or incompletely treated chronic periodontal disease, pregnancy or breastfeeding, history of radiation therapy to the head and/ or neck area, bisphosphonate use, and heavy smoking history of 20 cigarettes per day or more.

\section{Randomization and surgical procedures}

In total, 30 patients were single-blinded randomized in 1:1 ratio to the experimental and control arms using Sealed Envelope database (https://www.sealedenvelope.com). All implants (Implantium/NR-line; Dentium, Seoul, Korea, TSIII; Osstem, Seoul, Korea, Luna; Shinhung, Seoul, Korea, and SLA Bone level; Institute Straumann AG, Basel, Switzerland) were sandblasted, large-grit, acid-etched surface 
internal-type, and first surgery was performed according to the standard guideline of each manufacturing company. Implants were placed in the optimal position considering the occlusion and physiological shape. Following implant placement, GBR was performed after confirming a vertical dehiscence defect around the implant fixture using a periodontal probe (CP 15 UNC; Hu-friedy, Chicago, IL, USA). Deproteinized bovine bone mineral (BioOss; Geistlich Biomaterials, Wolhusen, Switzerland and CollaOss; Bioland, Cheongju, Korea) and DHT cross-linked collagen type I membrane (OssGuide; Bioland) were used for the experimental group, and BioOss and non-cross-linked type I and III collagen membrane (BioGide; Geistlich Biomaterials) were used for the control group. A total of 28 patients were included in the final analysis, after excluding 1 patient each from the experimental and control groups due to infection and screw exposure. At the time of the second surgery 16 weeks after the first surgery, radiological and clinical evaluation using cone-beam computed tomography (CBCT) as well as histological analysis using specimens collected via trephine bur were conducted prospectively. A baseline was established after final prosthesis. Eight patients in the experimental group and 1 patient in the control group were excluded because of refusal to attend regular followup. Finally, 6 patients in the experimental group and 13 patients in the control group were included in the final analysis with radiographic and clinical assessment, with a mean duration of follow-up of 41.4 months (Fig. 1, 2).

\section{Clinical and radiographic analysis}

Clinical and radiographic evaluations were performed 3 years after final prosthesis. Clinically, probing pocket depth was measured in 6 areas around the implants (mesio-buccal, mid-buccal, disto-buccal, mesio- palatal/lingual, midpalatal/lingual, and disto-palatal/lingual sides). The width

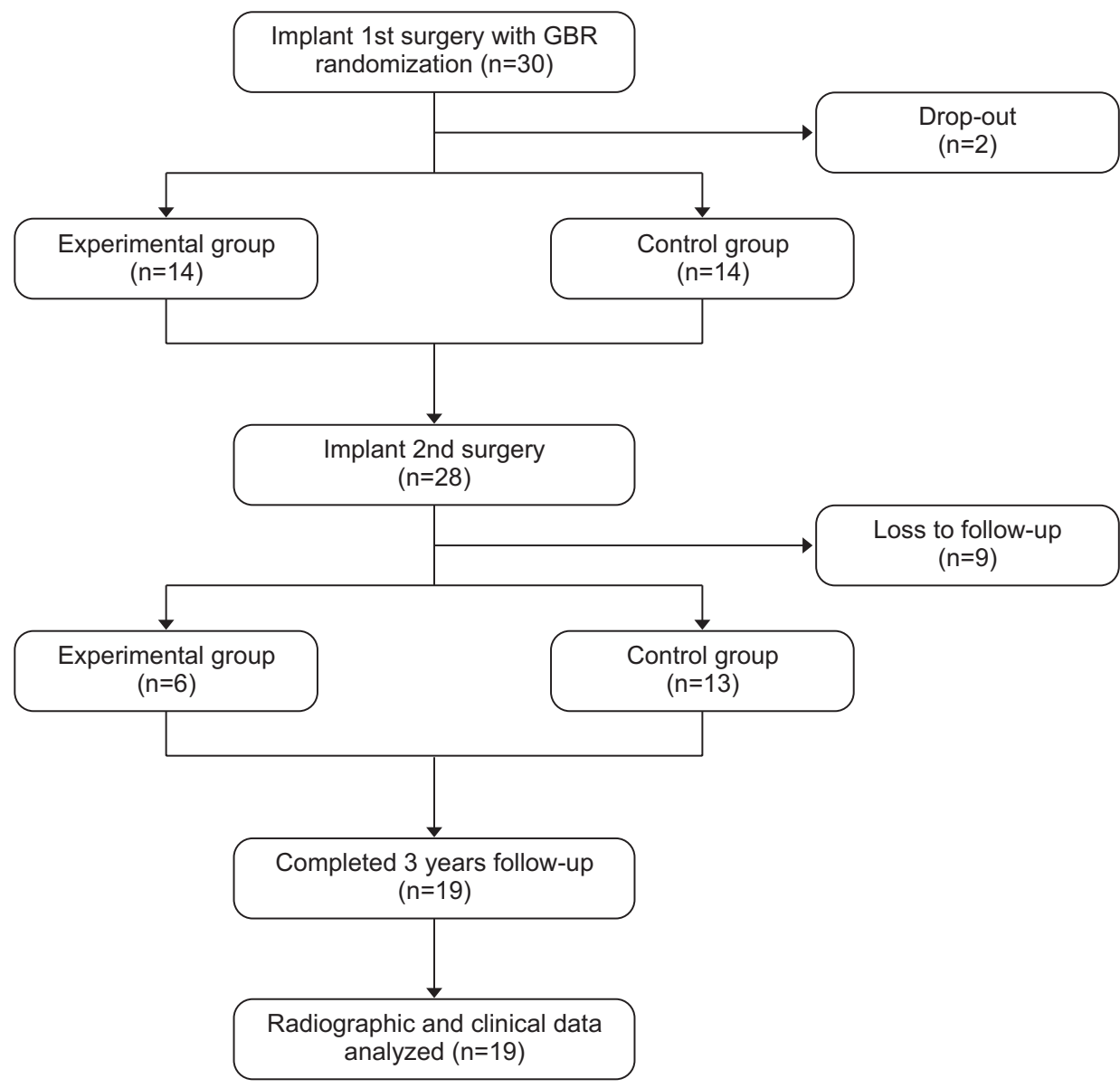

Fig. 1. Flow chart of the inclusion and exclusion of participants. GBR, guided bone regeneration; Experimental group, dehydrothermally cross-linked collagen membrane; Control group, non-cross-linked native collagen membrane. 


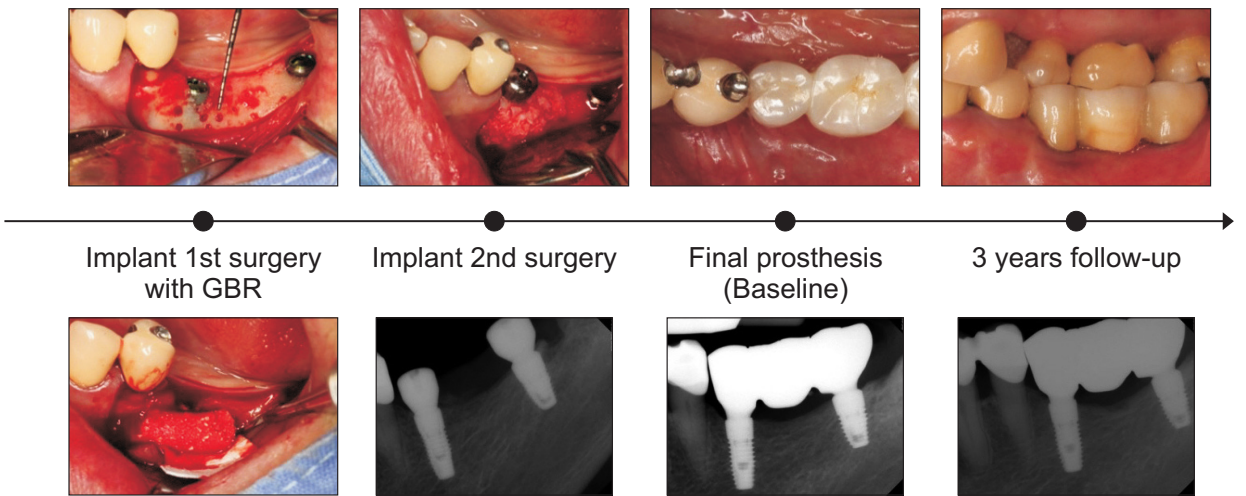

Fig. 2. Clinical photos and periapical radiographic images of the guided bone regeneration (GBR) technique. A baseline was established after final prosthesis.

Table 1. Demographic and baseline characteristics of study participants

\begin{tabular}{|c|c|c|c|c|}
\hline Variable & $\begin{array}{l}\text { Experimental group } \\
\qquad(n=6)\end{array}$ & $\begin{array}{l}\text { Control group } \\
(n=13)\end{array}$ & $\begin{array}{l}\text { Total } \\
(\mathrm{n}=19)\end{array}$ & $p$-value \\
\hline Sex & & & & 0.699 \\
\hline Male & 2 & 8 & 10 & \\
\hline Female & 4 & 5 & 9 & \\
\hline Age (y) & $60.3 \pm 10.0$ & $57.5 \pm 10.0$ & $58.4 \pm 10.1$ & 0.299 \\
\hline \multicolumn{5}{|l|}{ Position } \\
\hline Maxilla & & & & 0.826 \\
\hline Anterior & 2 & 2 & 4 & \\
\hline Premolar & 0 & 2 & 2 & \\
\hline Molar & 1 & 2 & 3 & \\
\hline Mandible & & & & 0.169 \\
\hline Anterior & 0 & 1 & 1 & \\
\hline Premolar & 3 & 1 & 4 & \\
\hline Molar & 0 & 5 & 5 & \\
\hline Diameter (mm) & & & & 0.542 \\
\hline Narrow $(<3.75)$ & 1 & 0 & 1 & \\
\hline Standard (3.75-5.0) & 5 & 11 & 16 & \\
\hline Wide $(\geq 5.0)$ & 0 & 2 & 2 & \\
\hline Length (mm) & & & & 0.082 \\
\hline Short $(<10.0)$ & 4 & 2 & 6 & \\
\hline Standard (10.0-13.0) & 2 & 11 & 13 & \\
\hline
\end{tabular}

Values are presented as number only or mean \pm standard deviation.

Experimental group, dehydrothermally cross-linked collagen membrane; Control group, non-cross-linked native collagen membrane. ${ }^{*} p$-values were calculated using the nonparametric chi-square and Mann-Whitney tests.

of attachment gingiva in the mesio-buccal, mid-buccal, and disto-buccal sides was also measured using a periodontal probe. Radiologically, the change in marginal bone level in the mesial and distal sides of the implant between baseline and 3-year follow-up was evaluated using periapical radiography. Additionally, changes in clinical crownto-implant (C/I) ratio was also evaluated using periapical radiography. Each periapical radiograph was corrected for distortion by confirming the length of implant and mea- sured using the PACS system (Infinitt PACS; Infinitt, Seoul, Korea).

\section{Statistical analysis}

Mean and standard deviation of clinical and radiological endpoints at baseline and 3 years in the experimental and control groups were measured and evaluated using the nonparametric chi-square and Mann-Whitney U tests. IBM 
SPSS Statistics (version 21.0; IBM Corp., Armonk, NY, USA) was used for statistical analysis, and statistical significance was defined as a $p$-value of 0.05 .

\section{RESULTS}

\section{Patient enrollment}

Of the 6 patients in the experimental group, 2 (33.3\%) were male, and $4(66.7 \%)$ were female. Of the 13 patients in the control group, 8 (61.5\%) were male, and 5 (38.5\%) were female ( $p=0.699)$. Patient age ranged from 42 to 78 years (mean age, 58.4 years); mean age in the experimental group and control group was 60.3 and 57.5 years, respectively $(p=0.299)$. Nine implants $(47.4 \%)$ were placed in the maxilla and $10(52.6 \%)$ in the mandible. Standard diameter (3.75 to $5 \mathrm{~mm}$ ) implants showed the highest frequency with $5(26.3 \%)$ in the experimental group and $11(57.9 \%)$ in the control group. Standard length (10.0 to $13.0 \mathrm{~mm}$ ) implants also showed the highest frequency with 11 (57.9\%) in the control group (Table 1).

\section{Radiographic findings}

On periapical radiographic evaluation of change in marginal bone level in the mesial and distal sides of the implant at baseline and at 3 years, the change in mesial marginal bone level in the experimental group and control group was $0.00 \pm 0.13 \mathrm{~mm}$ and $0.19 \pm 0.38 \mathrm{~mm}$, respectively, showing no statistically significant difference $(p=0.471)$. The change in distal marginal bone level was $0.27 \pm 0.48$ $\mathrm{mm}$ in the experimental group and $0.00 \pm 0.14 \mathrm{~mm}$ in the control group, also showing no statistically significant difference ( $p=0.152$ ). Additionally, change in clinical $\mathrm{C} / \mathrm{I}$ ratio was $1.48 \pm 0.25 \mathrm{~mm}$ in the experimental group and $1.45 \pm$ $0.12 \mathrm{~mm}$ in the control group at baseline, and $1.51 \pm 0.29$ $\mathrm{mm}$ in the experimental group and $1.42 \pm 0.23 \mathrm{~mm}$ in the control group at 3 years; there was no statistically significant difference at either time point $(p=0.773$ and $p=0.644$, respectively) (Table 2 and Fig. 3).

\section{Clinical findings}

At the end of the 3-year follow-up period, all patients in the experimental and control groups fulfilled the survival and success diagnostic criteria resulting in 100\% survival and success rates. Clinical probing of pocket depth, measured at 3 years after final prosthesis, showed no statistically significant difference between the experimental and control group in the mesio-buccal $(2.66 \pm 0.81 \mathrm{~mm}$ vs. 3.56 $\pm 1.23 \mathrm{~mm}, p=0.051)$, mid-buccal $(2.16 \pm 1.16 \mathrm{~mm}$ vs. 3.00 $\pm 0.57 \mathrm{~mm}, p=0.201)$, disto-buccal $(2.83 \pm 0.98 \mathrm{~mm}$ vs. 3.76 $\pm 1.09 \mathrm{~mm}, p=0.434)$, mesio-palatal/lingual $(3.00 \pm 1.26$ $\mathrm{mm}$ vs. $3.30 \pm 1.60 \mathrm{~mm}, p=0.059)$, mid-palatal/lingual ( 2.33 $\pm 0.81 \mathrm{~mm}$ vs. $3.15 \pm 1.21 \mathrm{~mm}, p=0.331$ ), and disto-palatal/ lingual $(3.00 \pm 1.09 \mathrm{~mm}$ vs. $3.61 \pm 1.26 \mathrm{~mm}, p=0.063)$ sides of the implant. The width of attached gingiva also did not show statistically significant differences between experimental and control group in the mesio-buccal $(2.16 \pm 2.31$ $\mathrm{mm}$ vs. $2.69 \pm 1.18 \mathrm{~mm}, p=0.744)$, mid-buccal $(2.00 \pm 2.09$ $\mathrm{mm}$ vs. $2.38 \pm 1.19 \mathrm{~mm}, p=0.690)$, and disto-buccal ( $2.66 \pm$ $3.07 \mathrm{~mm}$ vs. $2.69 \pm 1.18 \mathrm{~mm}, p=0.766$ ) sides of the implant (Table 3).

\section{DISCUSSION}

Many clinical studies suggest favorable results for GBR in the rehabilitation of bone defects around implants, but these results are limited to implants with concomitant GBR using DHT cross-linked collagen membranes and anorganic

Table 2. Changes in the marginal bone level and clinical C/I ratio from baseline to 3 years after final prosthesis

\begin{tabular}{lccc}
\hline \multicolumn{1}{c}{ Variable } & $\begin{array}{c}\text { Experimental } \\
\text { group } \\
(\mathbf{n}=\mathbf{6})\end{array}$ & $\begin{array}{c}\text { Control } \\
\text { group } \\
(\mathbf{n}=\mathbf{1 3})\end{array}$ & $\boldsymbol{p}$-value \\
\hline Marginal bone level (mm) & & & \\
$\quad$ Mesial of the implant & $0.00 \pm 0.13$ & $0.19 \pm 0.38$ & 0.471 \\
Distal of the implant & $0.27 \pm 0.48$ & $0.00 \pm 0.14$ & 0.152 \\
Clinical C/I ratio & & & \\
After final prosthesis & $1.48 \pm 0.25$ & $1.45 \pm 0.12$ & 0.773 \\
3-year follow-up & $1.51 \pm 0.29$ & $1.42 \pm 0.23$ & 0.644 \\
\hline
\end{tabular}

Values are presented as mean \pm standard deviation. C/I, crown to implant; Experimental group, dehydrothermally crosslinked collagen membrane; Control group, non-cross-linked native collagen membrane. 

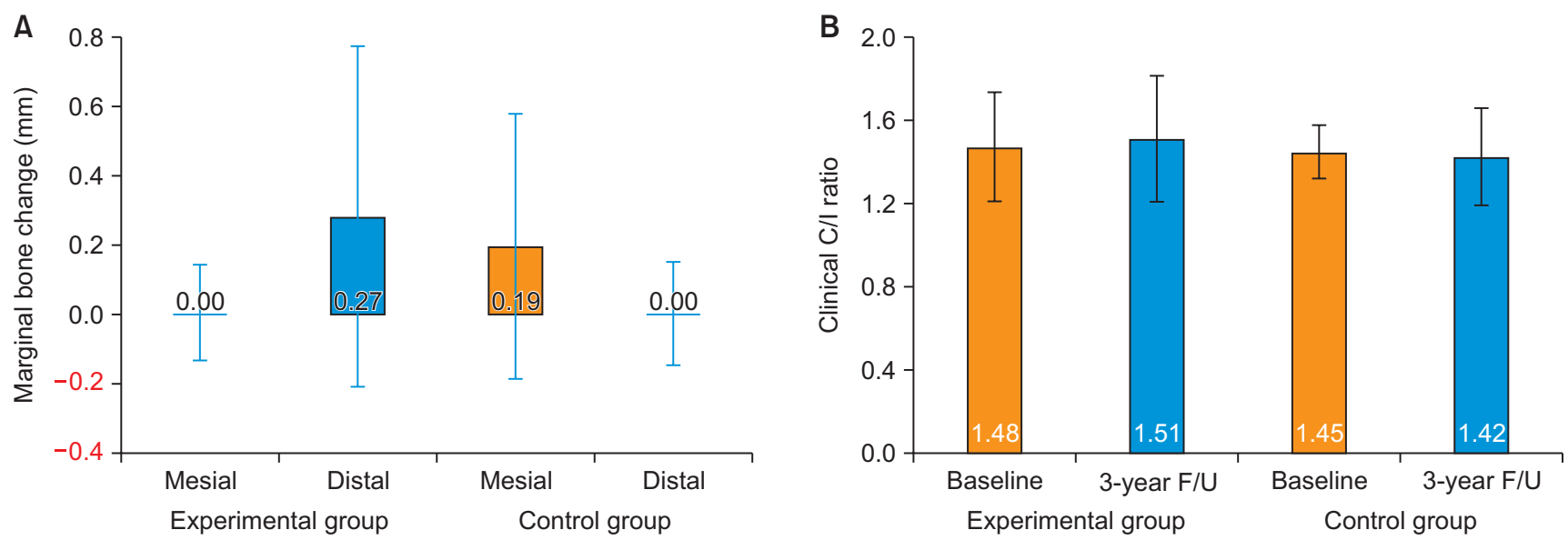

Fig. 3. Graphical comparison of changes in the marginal bone level (A) and clinical crown-to-implant (C/I) ratio (B) of the experimental and control groups from baseline to 3 years after final prosthesis. Experimental group, dehydrothermally cross-linked collagen membrane; Control group, non-cross-linked native collagen membrane; F/U, follow-up.

Table 3. Clinical outcome after 3-years of final prosthesis

\begin{tabular}{lccc}
\multicolumn{1}{c}{ Variable } & $\begin{array}{c}\text { Experimental group } \\
(\mathbf{n = 6})\end{array}$ & $\begin{array}{c}\text { Control group } \\
(\mathbf{n}=\mathbf{1 3})\end{array}$ & $\boldsymbol{p}$-value \\
\hline Probing pocket depth (mm) & & & $3.56 \pm 1.23$ \\
Mesio-buccal of the implant & $2.66 \pm 0.81$ & $3.00 \pm 0.57$ & 0.051 \\
Mid-buccal of the implant & $2.16 \pm 1.16$ & $3.76 \pm 1.09$ & 0.201 \\
Disto-buccal of the implant & $2.83 \pm 0.98$ & $3.30 \pm 1.60$ & 0.434 \\
Mesio-palatal/lingual of the implant & $3.00 \pm 1.26$ & $3.15 \pm 1.21$ & 0.059 \\
Mid-palatal/lingual of the implant & $2.33 \pm 0.81$ & $3.61 \pm 1.26$ & 0.063 \\
Disto-palatal/lingual of the implant & $3.00 \pm 1.09$ & & 0.744 \\
Width of attached gingiva (mm) & & $2.69 \pm 1.18$ & 0.690 \\
Mesio-buccal of the implant & $2.16 \pm 2.31$ & $2.38 \pm 1.19$ & 0.766 \\
Mid-buccal of the implant & $2.00 \pm 2.09$ & $2.69 \pm 1.18$ \\
Disto-buccal of the implant & $2.66 \pm 3.07$ &
\end{tabular}

Values are presented as mean \pm standard deviation.

Experimental group, dehydrothermally cross-linked collagen membrane; Control group, non-cross-linked native collagen membrane.

grafts [12,13]. Therefore, long-term studies on the viability, bone regeneration capacity and related biological effects, and bone maintenance in implants using DHT cross-linked collagen membranes in bone defects are very important for the clinical application of DHT cross-linked collagen membrane.

Biocompatibility and affinity of collagen membrane are critical factors to prevent unintended exposure and to reduce inflammation [5]. In this regard, low toxicity and high biocompatibility of non-cross-linked collagen are considered to have significant clinical advantages. Crosslinkage of collagen using chemical (glutaraldehyde [GTA]), hexamethylene diisocyanate [HMDI], and 1-ethyl-3-(3- dimethylaminopropyl) carbodiimide [EDC]), physical (DHT and ultra-violet [UV] irradiation), and biological (transglutaminase) methods are reported to compromise the biocompatibility and angiogenic ability of collagen membrane, and some studies showed that cross-linked collagen that remains in the periodontal tissue for an extended period of time may increase the incidence of major membranerelated adverse events, such as membrane exposure and infection $[14,15]$. This can be a disadvantage to using DHT cross-linked collagen membrane in clinical practice. However, according to our study, there was no confirmed case of adverse events due to membrane exposure or infection, except 1 case from each of the 2 groups with edema, red- 
ness, and pus around the implant.

GBR with DHT cross-linked collagen membrane is a representative method of physical crosslinking treatments, and many studies have reported outstanding mechanical properties and biocompatibility of DHT cross-linked collagen membranes. DHT cross-linking causes collagen membrane to have higher compressive and tensile strength and good resistance to enzymatic action [16,17]. Furthermore, the denaturation of collagen that occurs during the DHT cross-linking process reduces inflammatory reaction and increases cell infiltration [18]. Gough et al. [19] demonstrated low cytotoxicity of DHT cross-linked collagen film with less apoptosis of human osteoblasts compared with glutaraldehyde cross-linked collagen film. Moreover, many in vivo studies have shown that DHT cross-linked collagen membrane is a safe and effective material for GBR procedures [20,21].

Chiapasco and Zaniboni [22] reported in their systematic review that, in GBR performed on dehiscence or perforation around the implants, 20\% exposure or infection rate was observed with non-resorbable membranes and 5\% with resorbable membranes, with a mean cumulative survival rate of $95.7 \%$ (range, $84.7 \%$ to $100 \%$ ). Similarly, Donos et al. [23] also reported in another systematic review that the cumulative survival rate of implants with GBR was $91.7 \%$ to $100 \%$, which was not significantly different from the survival rate of $93.2 \%$ to $100 \%$ with implants without GBR. At the 3-years follow-up in the present study, 100\% implant viability was seen in both the experimental and control groups, including 9 patients who refused regular face-to-face assessment. However, this study would require a longer-term observation of implant survival, based on the previous findings of Simonis et al. [24] and AlNawas et al. [25] that the long-term cumulative implant survival rate at 10 years or longer is $89 \%$ to $90 \%$.

On radiological assessment, there was no significant difference in the 3-year mean marginal bone loss around the implants including the buccal, lingual, and palatal sides (experimental: $0.14 \pm 0.40 \mathrm{~mm}$ vs. control: $0.08 \pm 0.30 \mathrm{~mm}$ ) $(p=0.631)$. The 3 -year mean change in clinical $\mathrm{C} / \mathrm{I}$ ratio also did not show statistically significant differences between the two groups (experimental: $0.25 \pm 0.29 \mathrm{~mm}$ vs. control: $0.12 \pm 0.23 \mathrm{~mm})(p=0.557)$. On clinical evaluation, prob- ing pocket depth was $2.66 \pm 1.01 \mathrm{~mm}$ in the experimental group and $3.39 \pm 1.16 \mathrm{~mm}$ in the control group, showing no statistical significance, and the width of attached gingiva was $2.27 \pm 2.49 \mathrm{~mm}$ in the experimental group and 2.58 $\pm 1.18 \mathrm{~mm}$ in the control group, again showing no statistical significance $(p=0.732)$. Based on these radiological and clinical results, DHT cross-linked collagen membrane can be a useful tool in GBR around peri-implant dehiscence defects. Furthermore, based on a study in a rat cranial model that radiologically, histologically, and histometrically compared the bone regeneration efficacy between DHT cross-linked collagen membrane and non-cross-linked collagen membrane, similar biocompatibility, bone regeneration capacity, and bone maintenance were observed [20].

This study has several limitations. First, during the 3-year follow-up, only 6 patients in the experimental group, compared with 13 in the control group, had clinical and radiological results, which can compromise confidence in the comparison between the two groups. However, survival and success rates of the implants were monitored through surveys among patients not included in the final analysis, which confirmed that all 28 of the single implants were successfully maintained during the 3 years. Second, CBCT was not performed for long-term follow-up in order to reduce radiation as per the as low as reasonably achievable (ALARA) principle, which prevented radiological assessment of horizontal bone change, which was one of the markers used in the prospective study. Additionally, we did not use a stent to ensure measurement of the identical areas at all time points, which can be considered another limitation. Last, this study evaluated a limited number of subjects, which prevented the between-group comparison of age, sex, baseline systemic disease, smoking history, diameter and length of implant, and location of implant placement. Despite such limitations, this randomized study confirmed the biocompatibility and clinical usefulness of DHT cross-linked collagen membrane, which were similar to those of non-cross-linked collagen membrane.

\section{ACKNOWLEDGEMENTS}

This research was supported by the Basic Science Research Program through the National Research Foundation 
of Korea (NRF) funded by the Ministry of Science, ICT \& Future Planning (NRF-2017R1C1B5014849).

\section{CONFLICTS OF INTEREST}

The authors declare that they have no competing interests.

\section{ORCID}

\author{
Jae-Hong Lee \\ https://orcid.org/0000-0002-2375-0141 \\ Su-Hyun Park \\ https://orcid.org/0000-0003-1324-9713 \\ Do-Hyung Kim \\ https://orcid.org/0000-0001-7846-6175 \\ Ui-Won Jung \\ https://orcid.org/0000-0001-6371-4172
}

\section{REFERENCES}

1. Benic GI, Joo MJ, Yoon SR, Cha JK, Jung UW. Primary ridge augmentation with collagenated xenogenic block bone substitute in combination with collagen membrane and rhBMP-2: a pilot histological investigation. Clin Oral Implants Res 2017;28:1543-1552. doi: 10.1111/clr.13024.

2. Greenstein G, Cavallaro J, Romanos G, Tarnow D. Clinical recommendations for avoiding and managing surgical complications associated with implant dentistry: a review. J Periodontol 2008;79:1317-1329. doi: 10.1902/ jop.2008.070067.

3. Bornstein MM, Bosshardt D, Buser D. Effect of two different bioabsorbablecollagen membranes on guided bone regeneration: a comparative histomorphometric study in the dog mandible. J Periodontol 2007;78:1943-1953. doi: 10.1902/jop.2007.070102.

4. Hämmerle CH, Jung RE. Bone augmentation by means of barrier membranes. Periodontol 2000 2003;33:36-53. doi: 10.1046/j.0906-6713.2003.03304.x.

5. Bunyaratavej P, Wang HL. Collagen membranes: a review. J Periodontol 2001;72:215-229. doi: 10.1902/ jop.2001.72.2.215.

6. Schwartzmann M. Use of collagen membranes for guided bone regeneration: a review. Implant Dent 2000;9:63-66. doi: 10.1097/00008505-200009010-00011.

7. Sela MN, Kohavi D, Krausz E, Steinberg D, Rosen G. Enzymatic degradation of collagen-guided tissue regeneration membranes by periodontal bacteria. Clin Oral Implants Res
2003;14:263-268. doi: 10.1034/j.1600-0501.2003.140302.

$\mathrm{x}$.

8. Jung RE, Fenner N, Hämmerle CH, Zitzmann NU. Long-term outcome of implants placed with guided bone regeneration (GBR) using resorbable and non-resorbable membranes after 12-14 years. Clin Oral Implants Res 2013;24:10651073. doi: 10.1111/j.1600-0501.2012.02522.x.

9. Drexler JW, Powell HM. Dehydrothermal crosslinking of electrospun collagen. Tissue Eng Part C Methods 2011;17:9-17. doi: 10.1089/ten.TEC.2009.0754.

10. Schwarz F, Sager M, Rothamel D, Herten M, Sculean A, Becker J. [Use of native and cross-linked collagen membranes for guided tissue and bone regeneration]. Schweiz Monatsschr Zahnmed 2006;116:1112-1123. German.

11. Lee JH, Lee JS, Baek WS, Lim HC, Cha JK, Choi SH, Jung UW. Assessment of dehydrothermally cross-linked collagen membrane for guided bone regeneration around periimplant dehiscence defects: a randomized single-blinded clinical trial. J Periodontal Implant Sci 2015;45:229-237. doi: 10.5051/jpis.2015.45.6.229.

12. Retzepi M, Donos N. Guided bone regeneration: biological principle and therapeutic applications. Clin Oral Implants Res 2010;21:567-576. doi: 10.1111/j.16000501.2010.01922.x.

13. Locci P, Calvitti M, Belcastro S, Pugliese M, Guerra M, Marinucci L, Staffolani N, Becchetti E. Phenotype expression of gingival fibroblasts cultured on membranes used in guided tissue regeneration. J Periodontol 1997;68:857-863. doi: 10.1902/jop.1997.68.9.857.

14. Becker J, Al-Nawas B, Klein MO, Schliephake H, Terheyden H, Schwarz F. Use of a new cross-linked collagen membrane for the treatment of dehiscence-type defects at titanium implants: a prospective, randomizedcontrolled double-blinded clinical multicenter study. Clin Oral Implants Res 2009;20:742-749. doi: 10.1111/j.16000501.2008.01689.x.

15. Annen BM, Ramel CF, Hämmerle $\mathrm{CH}$, Jung RE. Use of a new cross-linked collagen membrane for the treatment of peri-implant dehiscence defects: a randomised controlled double-blinded clinical trial. Eur J Oral Implantol 2011;4:87-100.

16. Haugh MG, Jaasma MJ, O'Brien FJ. The effect of dehydrothermal treatment on the mechanical and structural properties of collagen-GAG scaffolds. J Biomed Mater Res A 2009;89:363-369. doi: 10.1002/jbm.a.31955.

17. Weadock KS, Miller EJ, Bellincampi LD, Zawadsky JP, Dunn MG. Physical crosslinking of collagen fibers: comparison of ultraviolet irradiation and dehydrothermal treatment. J Biomed Mater Res 1995;29:1373-1379. doi: 10.1002/ jbm.820291108.

18. Koide M, Osaki K, Konishi J, Oyamada K, Katakura T, Takahashi A, Yoshizato K. A new type of biomaterial for artificial skin: dehydrothermally cross-linked composites 
of fibrillar and denatured collagens. J Biomed Mater Res 1993;27:79-87. doi: 10.1002/jbm.820270111.

19. Gough JE, Scotchford CA, Downes S. Cytotoxicity of glutaraldehyde crosslinked collagen/poly(vinyl alcohol) films is by the mechanism of apoptosis. J Biomed Mater Res 2002;61:121-130. doi: 10.1002/jbm.10145.

20. An YZ, Heo YK, Lee JS, Jung UW, Choi SH. Dehydrothermally cross-linked collagen membrane with a bone graft improves bone regeneration in a rat calvarial defect model. Materials (Basel) 2017;10:E927. https://doi.org/10.3390/ ma10080927.

21. An YZ, Kim YK, Lim SM, Heo YK, Kwon MK, Cha JK, Lee JS, Jung UW, Choi SH. Physiochemical properties and resorption progress of porcine skin-derived collagen membranes: in vitro and in vivo analysis. Dent Mater J 2018;37:332-340. doi: 10.4012/dmj.2017-065.

22. Chiapasco M, Zaniboni M. Clinical outcomes of GBR pro- cedures to correct peri-implant dehiscences and fenestrations: a systematic review. Clin Oral Implants Res 2009;20 Suppl 4:113-123. doi: 10.1111/j.1600-0501.2009.01781.x.

23. Donos N, Mardas N, Chadha V. Clinical outcomes of implants following lateral bone augmentation: systematic assessment of available options (barrier membranes, bone grafts, split osteotomy). J Clin Periodontol 2008;35(8 Suppl):173-202. doi: 10.1111/j.1600-051X.2008.01269.x.

24. Simonis P, Dufour T, Tenenbaum H. Long-term implant survival and success: a 10-16-year follow-up of nonsubmerged dental implants. Clin Oral Implants Res 2010;21:772-777. doi: 10.1111/j.1600-0501.2010.01912.x.

25. Al-Nawas B, Kämmerer PW, Morbach T, Ladwein C, Wegener J, Wagner W. Ten-year retrospective follow-up study of the TiOblast dental implant. Clin Implant Dent Relat Res 2012;14:127-134. doi: 10.1111/j.1708-8208.2009.00237.x. 